\title{
Pattern and quality of care of cancer pain management. Results from the Cancer Pain Outcome Research Study Group
}

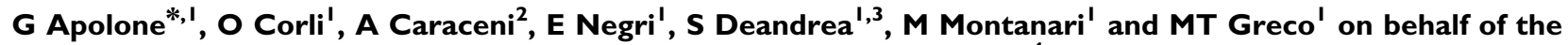 \\ Cancer Pain Outcome Research Study Group (CPOR SG) Investigators ${ }^{4}$ \\ 'Center for the Evaluation and Research on Pain (CERP) Department of Oncology, Istituto di Ricerche Farmacologiche 'Mario Negri', Milan, Italy; \\ ${ }^{2}$ Palliative Care Unit, Department of Anesthesiology and Palliative Care, Fondazione IRCCS Istituto Nazionale dei Tumori, Milan, Italy; ${ }^{3}$ Institute of Medical \\ Statistics and Biometry, University of Milano, Milan, Italy
}

Most patients with advanced or metastatic cancer experience pain and despite several guidelines, undertreatment is well documented. A multicenter, open-label, prospective, non-randomised study was launched in Italy in 2006 to evaluate the epidemiology, patterns and quality of pain care of cancer patients. To assess the adequacy of analgesic care, we used a standardised measure, the pain management index (PMI), that compares the most potent analgesic prescribed for a patient with the reported level of the worst pain of that patient together with a selected list of clinical indicators. A total of I I 0 centres recruited I 80 I valid cases. $61 \%$ of cases were received a $\mathrm{WHO}$-level III opioid; $25.3 \%$ were classified as potentially undertreated, with wide variation (9.8$55.3 \%)$ according to the variables describing patients, centres and pattern of care. After adjustment with a multivariable logistic regression model, type of recruiting centre, receiving adjuvant therapy or not and type of patient recruited (new or already on followup) had a significant association with undertreatment. Non-compliance with the predefined set of clinical indicators was generally high, ranging from 41 to $76 \%$. Despite intrinsic limitations of the PMI that may be considered as an indicator of the poor quality of cancer pain care, results suggest that the recourse to WHO third-level drugs still seems delayed in a substantial percentage of patients. This delay is probably related to several factors affecting practice in participating centres and suggests that the quality of cancer pain management in Italy deserves specific attention and interventions aimed at improving patients' outcomes.

British Journal of Cancer (2009) I 00, I566- I574. doi:I0.1038/sj.bjc.6605053 www.bjcancer.com

Published online 28 April 2009

(C) 2009 Cancer Research UK

Keywords: cancer pain; opioids; quality; PMI

Pain is a major problem for patients with cancer. Meta-analyses report that most patients with advanced or metastatic cancer experience pain (Hearn and Higginson, 2003; van den Beuken-van Everdingen et al, 2007). Although several guidelines for cancer pain management have been published since 1986 (Jacox et al, 1994; WHO, 1996; Hanks et al, 2001; Cohen et al, 2003; SIGN, 2008), undertreatment is well documented and can reach $82 \%$ of patients in some settings (Di Maio et al, 2004). A recent systematic review based on 26 papers published from 1994 to 2007 suggests that nearly one of two patients with cancer pain is undertreated with a wide variability across studies and settings (Deandrea et al, 2008). Undertreatment is usually attributed to inappropriate use of opioids on account of several reasons related to the healthcare provider, patient, family, institution and society (Maltoni, 2008), where fear of opioids may be the most important determinant from the patient's point of view (Reid et al, 2008).

In Italy, opioid consumption rates are yet among the lowest in Europe (De Conno et al, 2005), although last year there was a small increase, mainly because of a change in the type of drugs prescribed than to an increase in the number of patients treated

*Correspondence: Dr G Apolone; E-mail: apolone@marionegri.it

${ }^{4}$ See Appendix

Received 23 September 2008; revised 20 March 2009; accepted 27 March 2009; published online 28 April 2009
(Osservatorio Nazionale sull'impiego dei farmaci, 2007). As recently pointed out, poor information and communication may be a further barrier to a correct access to analgesic and palliative care and to hospice admission (Harrington and Smith, 2008).

To improve the quality of cancer pain management, the Mario Negri Institute implemented a project on 2004 in Italy (Apolone et al, 2004, 2006a), and an Outcome Research study was launched in 2006. The objectives were (a) to describe a large cohort of cancer patients in terms of pain characteristics, patterns of care and patient-reported outcomes; (b) to assess the quality of analgesic treatments in terms of congruence between the reported level of pain intensity of patients and the potency of the prescribed analgesic drug; (c) to compare the effects of various analgesic options, using appropriate statistical methods, such as the propensity score. This study reports on details about the design of the study, the type of patients recruited, the analgesic drugs prescribed and the quality of analgesic care administered.

\section{PATIENTS AND METHODS}

\section{Study design and patients}

Background and methods are described elsewhere (Apolone et al, 2006a, b, 2008). Briefly, the data reported here were collected as part of a multicentre, open-label, prospective, non-randomised 


\begin{tabular}{|l|c|c|c|c|}
\cline { 2 - 5 } \multicolumn{1}{c|}{} & \multicolumn{4}{c|}{ WHO analgesic drug level } \\
\hline \multicolumn{1}{c|}{ Pain intensity } & $\begin{array}{c}\text { No drugs } \\
(0)\end{array}$ & $\begin{array}{c}\text { NSAID } \\
(\mathrm{I})\end{array}$ & $\begin{array}{c}\text { Weak opioids } \\
\text { (II) }\end{array}$ & $\begin{array}{c}\text { Strong opioids } \\
\text { (III) }\end{array}$ \\
\hline No pain (0) & 0 & +1 & +2 & +3 \\
\hline Mild (1-3) & -1 & 0 & +1 & +2 \\
\hline Moderate (4-7) & -2 & -1 & 0 & +1 \\
\hline Severe (8-10) & -3 & -2 & -1 & 0 \\
\hline
\end{tabular}

Figure I Pain management index.

study. Each centre admitted up to 25 patients with diagnostic evidence of advanced/metastatic solid tumour; persistent pain, of any degree of intensity related to cancer, requiring or already on analgesic treatment; age $\geqslant 18$ years; life expectancy more than 1 month; and able to read, understand and provide informed consent to participate.

After enrolment/inclusion, the following screening assessments were carried out and recorded weekly for the first month, with a final visit at week 12 (at the end of the study): (a) medical history including cancer history, (b) physical examination, (c) record of medications and recent therapies, including analgesic consumption, (d) pain and symptom assessment, (f) patients' and physicians' satisfaction with pain treatment and (g) patient's self-reported quality of life.

\section{Outcomes and endpoints}

Patients' and physicians' reports were collected using standardised forms at scheduled visits. Self-administered questionnaires were completed when the patient attended regular visits at the centre or during admission or at home depending on the setting of care. Investigators recorded information about patients and disease, pain medications and type and number of rescue doses in a case report form.

Pain characteristics (intensity, relief and so on) were the primary outcome measures. Other patient-reported outcomes were collected too, such as satisfaction with care, quality of life and symptoms. Pain was measured using five items from the Italian version of the Brief Pain Inventory (Caraceni et al, 1996) assessing intensity of worst, present, least and average pain and pain relief with an 11-point numerical rating scale.

We used two methods to evaluate the analgesic undertreatment. First, we applied the pain management index (PMI), developed by Cleeland et al (1994). According to the World Health Organisation's (WHO) guidelines for the management of pain in cancer, treatment is considered adequate when there is congruence between the reported level of pain of the patient and the potency of the prescribed analgesic drug (its place on the WHO analgesic ladder; WHO, 1996). The PMI compares the most potent analgesic prescribed for a patient with the reported level of the worst pain of that patient.

To construct the index, we determined which of four levels of analgesic drug therapy was the most potent one used: 0 , no analgesic drug; 1, a non-opioid (e.g., a non-steroidal antiinflammatory drug); 2, a weak opioid (e.g., codeine or tramadol); and 3, a strong opioid (e.g., morphine, fentanyl, buprenorphine, oxycodone and so on). We then determined the patient's level of pain from the Brief Pain Inventory (1-3, mild; 4-7, moderate; $8-10$, severe). No pain was scored as 0 ; mild pain, 1 ; moderate pain, 2; and severe pain, 3 . The PMI, computed by subtracting the pain level from the analgesic level, ranges from -3 (a patient with severe pain receiving no analgesic drugs) to +3 (a patient receiving morphine or an equivalent and reporting no pain). Negative scores are considered to indicate pain undertreatment, and scores of 0 or higher are considered a conservative indicator of acceptable treatment (see Figure 1).

As the PMI provides only a rough estimate of how pain is treated in a sample taking into account only some attributes of the pain characteristics (Deandrea et al, 2008), we also assembled a list of clinical indicators to capture the appropriateness of the analgesic care delivered more directly. Operationally, we identified four specific clinical conditions where there was evidence that pain should be treated with a specific approach according to available guidelines: presence of episodes of breakthrough pain to be treated with a strong opioid as rescue/escape therapy, presence of neuropathic pain to be treated with a specific adjuvant drug, pain with intensity higher than 7 points, calling for a strong opioid as around-the-clock therapy, and presence of bone metastasis to be treated with bisphosphonates, (Hanks et al, 2001; Wong and Wiffen, 2002; CEVEAS, 2004; SIGN, 2008). Then, we estimated the proportion of patients in each group who did not receive the recommended therapy, as additional indicators of the quality of analgesic therapy. Frequencies were then associated with some variables, such as type of patient and recruiting centre.

Given the large number of centres, we used a web-based system to optimise the handling of all aspects of the clinical study, including data entry, quality assurance and validation. A general data entry engine for clinical trials developed by the Mario Negri Institute was used, which was compliant with current laws concerning ethical and regulatory issues (Clivio et al, 2006). Before implementation, it was tested with a pilot feasibility study in 130 centres in 2005.

\section{Statistical analysis}

On the basis of the literature and the results of the pilot study in 2005, we assumed that 100 centres during a 2-month inception period (recruitment) could see and evaluate up to 2500 eligible cases. We also assumed that at least half would already be receiving a WHO level III treatment and most of the others would eventually need a WHO level III analgesic during the longitudinal evaluation period.

There were no formal estimates of the proportion of cases who might be classified as undertreated at inclusion, although, on the basis of a systematic review of the literature pertaining to the PMI (Deandrea et al, 2008), it was expected that up to $40 \%$ of patients might be receiving, at the time of study inclusion, an analgesic treatment not adequate to their intensity of pain. All patients enrolled in the study and eligible were included in the present analysis.

In the descriptive analysis, absolute frequency was used for categorical variables and central trend and dispersion measurements (mean, median and s.d.) for quantitative continuous variables. When comparing groups, $\chi^{2}$-tests for associations were used for categorical variables, such as whether or not patients experienced a given event. For continuous variables, such as mean differences in pain intensity, $t$-tests or one-way-analysis of variance, were used. For binary dependent variables, such as whether or not the patient had an analgesic undertreatment according to the PMI, estimates of association with potential independent variables were expressed in terms of odds ratios (ORs). After univariate analysis, a logistic model was fitted using maximum likelihood estimation to express the odds of each variable relative to the reference category, after adjustment for all other covariates. For example, the risk of being classified as 


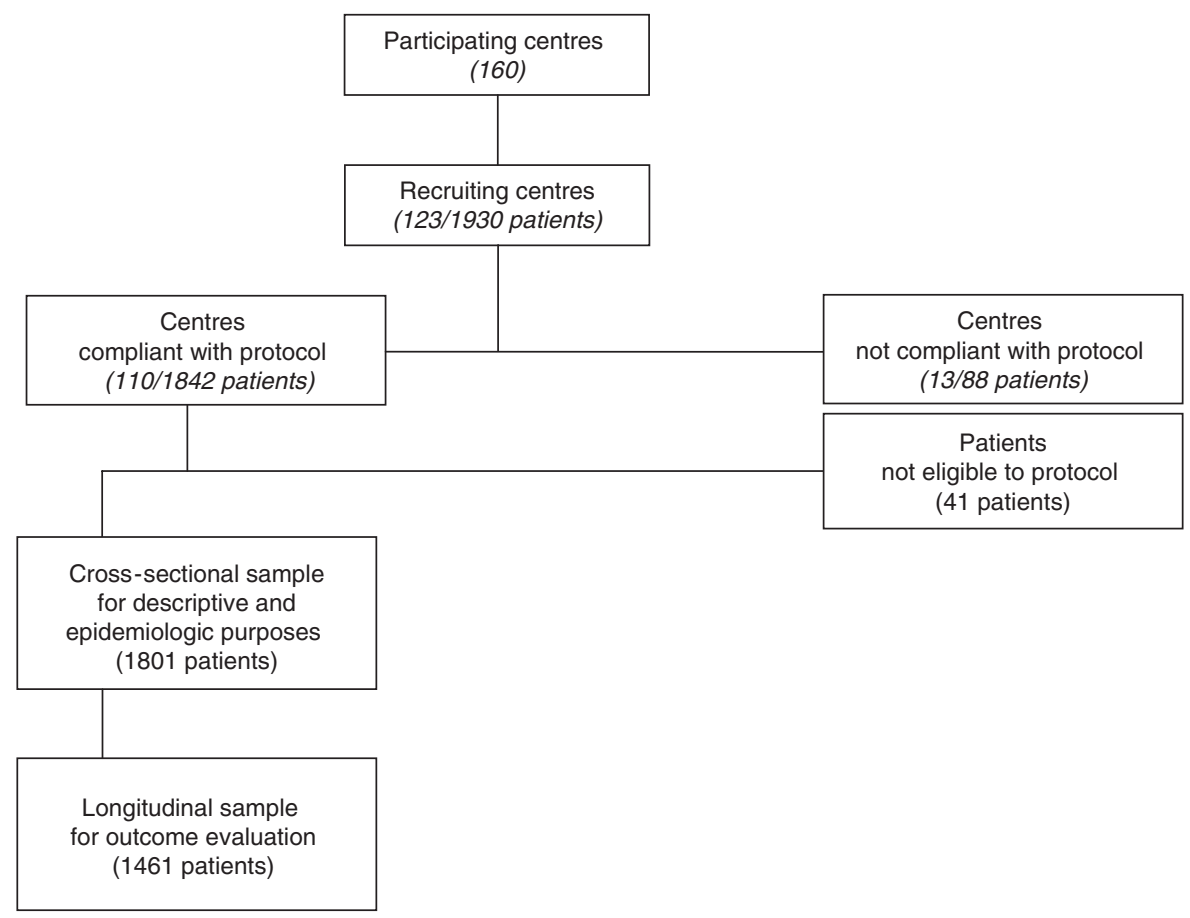

Figure 2 Synopsis of the stages of the study.

undertreated for a patient with 70 years of age or more was compared to one younger than 51 years, given the same sex, type of cancer and analgesic adjuvant therapy. In addition, $95 \%$ confidence intervals of the ORs were computed.

Given the observational nature of the study, the relatively large sample size and the number of statistical tests, $P$-values must be considered with cautions as merely suggestive of a trend.

\section{Ethical considerations}

The study complied with Italian requirements for observational studies. The protocol was approved by the local research ethics committees of participating centres. All patients gave written informed consent to participate in the study. The full study protocol was published in an open-access journal before the study started (Apolone et al, 2006b).

\section{RESULTS}

As shown in Figure 2, 110 centres recruited 1801 valid cases that constitute the baseline cross-sectional sample, from February 2006 to March 2007. There were 1461 patients with complete data at 28 days and they form the longitudinal sample. This study focuses on the baseline sample.

As shown in Table 1, patients recruited were more frequently male, and had severe pain (mean worst pain at baseline 6.8). Half had bone metastasis, episodes of breakthrough pain and were still on active anticancer treatment. The most frequent primary cancers were lung, breast and colorectal cancers. Nearly two-thirds were recruited by oncologic centres, and the majority were not aware of their prognosis. Most had already been admitted at the centre when enrolled in the study. In all, $61 \%$ of patients were received a WHO-level III opioid, fentanyl and buprenorphine transdermal delivery systems being the most widely prescribed (in about $39 \%$ of cases); $47 \%$ received some kind of rescue/escape therapy, which was an anti-inflammatory drug in $53 \%$ of cases; oral morphine was the most widely prescribed strong opioid as recue therapy. A total of $60 \%$ also received some kind of adjuvant analgesic therapy.
We first assembled the PMI using all four items of the Brief Pain Inventory. Table 2 shows, as expected, that different pain items generated different undertreatment estimates (8.9-25.3\%). As recommended by Cleeland et al (1994), we used the worst pain item as main outcome. According to the literature suggesting wide variations on the basis of several variables related to patients, centres and settings (Deandrea et al, 2008), we first conducted a bivariate analysis to identify the potential predictors of undertreatment, then a multivariable analysis to estimate the effect of each potential confounder on the association between predictors and occurrence of undertreatment. Tables $3-5$ report the results of both analyses.

When patients were classified according to the time of the follow-up or treatment before inclusion (new incident cases vs patients already in follow-up at the centre), there was a clear tendency: the proportion of undertreatment ranged from 44.7 to $20.2 \%$ with a consistent and statistically significant gradient $(P<0.0001)$. Among the other potential predictors tested with univariate analyses, the absence of bone metastasis and ongoing chemotherapy, being recruited in pain and palliative centres, having a colorectal cancer, and not receiving adjuvant analgesic therapy, were significantly associated with a higher probability of being classified as undertreated $(\mathrm{OR}=>1.2$ and $P<0.05)$. After multivariable logistic regression, only type of recruiting centre $(P<0.01)$, receiving adjuvant therapy or not $(P<0.001)$, and type of patient recruited (new or already on follow-up; $P<0.01$ ) showed a significant association with undertreatment. To describe the effect of these three variables better, we assembled a new composite variable comprising all the possible mutually exclusive combinations of the original predictors transposed to 12 possible levels where we estimated the prevalence of undertreatment. Estimates ranged from 9.8 (patients already admitted to hospice, receiving adjuvant therapy) to $55.3 \%$ (new cases admitted to pain or palliative care centre, not receiving adjuvant treatment). Figure 3 confirms that each of the three variables actually has an effect on the occurrence of undertreatment, and within each type of recruiting centre, the other two variables may stratify patients with different frequency. Nevertheless, patients in a hospice had a lower prevalence $($ range $=9.8-30.4 \%$ ) than those in oncology 
Table I Characteristics of patients at baseline $(n=|80|)$

\begin{tabular}{|c|c|c|c|c|c|}
\hline Characteristics & $\%$ & Mean, s.d. & Characteristics & $\%$ & Mean, s.d. \\
\hline Age & & $63.9,12.1$ & Only weak opioids & 3.8 & \\
\hline Female & 47.3 & & NSAID with weak opioids & 2.9 & \\
\hline \multirow[t]{2}{*}{ Karnofsky PS, <50 } & 11.5 & & One strong opioid & 11.8 & \\
\hline & & & NSAID/weak opioid+strong opioid & 3.2 & \\
\hline Primary tumour & & & More than one strong opioid & 0.2 & \\
\hline Lung & 21.8 & & & & \\
\hline Breast & 15.9 & & Adjuvant therapy & & \\
\hline Colorectal & 13.7 & & Corticosteroids & 40.1 & \\
\hline Prostate & 7.9 & & Anticonvulsants & 15.8 & \\
\hline Gynecological & 6.1 & & Antidepressants & 10.8 & \\
\hline Pancreas & 6.0 & & Bisphosphonates & 18.5 & \\
\hline
\end{tabular}

Genitourinary

Stomach

Liver $\quad 1.2$

Others $\quad 9.9$

Unknown $\quad 1.4$

$\begin{array}{ll}\text { Bone metastasis } & 46.8\end{array}$

Earlier surgery $\quad 58.0$

Earlier chemotherapy $\quad 65.2$

Earlier hormonotherapy $\quad 20.0$

Earlier radiotherapy $\quad 40.3$

Others $\quad 5.4$

Ongoing chemotherapy $\quad 49.0$

Patients aware of prognosis (reported by physician) 30.3

Type of recruiting centre

Oncology centre

Palliative care

Pain centre

Hospice

Others

Time of recruiting

New cases

Already admitted

Pain intensity $(0-10)$

Worst (previous week)

Mean (previous week)

Current

Least (previous week)

Pain intensity (according to WHO)

None

Mild

Moderate

Severe

Pain relief $(0-100)$

Patients with breakthrough pain

Patients with neuropathic pain

Type of analgesic care

Around the clock therapy

None

Only NSAID

Only weak opioids

NSAID with weak opioids

One strong opioid

NSAID/weak opioid+strong opioid

More than one strong opioid

Rescue therapy

None

Only NSAID
Table I (Continued)

Table 2 Percentages of patients with negative PMI score for different pain items (from Brief Pain Inventory)

Time of recruiting

\begin{tabular}{lrcc} 
Pain & All & Already admitted & New patients \\
\hline Worst pain & 25.3 & 20.4 & 38.3 \\
Least pain & 8.9 & 6.0 & 16.7 \\
Current pain & 12.2 & 8.5 & 22.0 \\
Mean pain & 14.6 & 11.3 & 23.7 \\
Overall pain (four items) & 14.0 & 11.1 & 21.8 \\
\hline
\end{tabular}

Table 3 Percentages of patients with negative PMI scores according to the type of recruitment (new patients or patients already admitted at the time of inclusion in the study)

\begin{tabular}{|c|c|c|c|c|}
\hline & \multicolumn{4}{|c|}{ Days since admission to the centre } \\
\hline & 0 (new patients) & $1-7$ & $8-27$ & $>\mathbf{2 7}$ \\
\hline$N$ & 282 & 171 & 210 & $1|0|$ \\
\hline \multicolumn{5}{|l|}{ PMI negative scores } \\
\hline$n$ & 126 & 48 & 46 & 222 \\
\hline$\%$ & 44.7 & 28.1 & 21.9 & 20.2 \\
\hline Cochran-Armitage trend test & $\begin{array}{l}\chi^{2}=8.124 \\
P<0.0001\end{array}$ & & & \\
\hline Heterogeneity test & $\begin{array}{c}\text { Statistic }=73.8092 \\
P<0.0001\end{array}$ & & & \\
\hline
\end{tabular}

centres $(16.3-39.3 \%)$ and pain and palliative centres (11.8$55.3 \%)$.

Table 6 shows the prevalence of patients receiving the treatment that we considered appropriate for each specific condition, and the associations with type of patient and type of centre. Noncompliance with the treatments identified was generally high, with some variability according to the type of patient and the recruiting centre. New cases had higher non-compliance rates in general. In patients with neuropathic pain, non-compliance was higher in oncology centres; in patients with severe worst pain, noncompliance rates were higher in palliative and pain centres.

\section{DISCUSSION}

Advances in diagnosis and therapy have extended the life expectancy of cancer patients, but for most of them, the last part of their life is impaired by pain, depression and other symptoms 
Table 4 Percentages of patients with negative PMI scores according to selected variables

\begin{tabular}{|c|c|c|c|c|c|}
\hline & $\mathbf{N}$ & $\%$ & OR & $95 \% \mathrm{Cl}$ & $P$-value \\
\hline \multicolumn{6}{|l|}{ Age (years) } \\
\hline$<51$ & 254 & 22.8 & 1.00 & - & - \\
\hline $51-60$ & 402 & 25.4 & 1.15 & $0.79-1.66$ & 0.4610 \\
\hline $61-70$ & 558 & 23.5 & 1.04 & $0.73-1.47$ & 0.8415 \\
\hline$>70$ & 583 & 28.0 & 1.31 & $0.93-1.85$ & 0.1227 \\
\hline \multicolumn{6}{|l|}{ Sex } \\
\hline Male & 947 & 24.2 & 1.00 & - & - \\
\hline Female & 850 & 26.5 & 1.13 & $0.91-1.40$ & 0.2650 \\
\hline \multicolumn{6}{|l|}{ Bone metastasis } \\
\hline Yes & 842 & 22.3 & 1.00 & - & - \\
\hline No & 955 & 27.9 & 1.34 & $1.08-1.67$ & 0.0072 \\
\hline \multicolumn{6}{|c|}{ Ongoing chemotherapy } \\
\hline Yes & 883 & 23.0 & 1.00 & - & - \\
\hline No & 914 & 27.5 & 1.27 & $1.02-1.57$ & 0.0294 \\
\hline \multicolumn{6}{|c|}{ Type of recruiting centre } \\
\hline Oncology centre & 1066 & 23.7 & 1.48 & $0.93-2.35$ & 0.0978 \\
\hline Pain center & 271 & 34.0 & 2.44 & $1.47-4.05$ & 0.0006 \\
\hline Palliative care & 307 & 26.1 & 1.67 & $1.01-2.78$ & $0.047 \mid$ \\
\hline Hospice & 138 & 17.4 & 1.00 & - & - \\
\hline Others & 15 & 33.3 & 2.38 & $0.74-7.58$ & 0.1440 \\
\hline \multicolumn{6}{|l|}{ Type of cancer ${ }^{a}$} \\
\hline NSCLC & 391 & 22.5 & 1.15 & $0.67-1.98$ & 0.6214 \\
\hline Breast & 287 & 23.7 & 1.23 & $0.70-2.15$ & 0.4757 \\
\hline Colorectal & 247 & 31.2 & 1.79 & $1.02-3.13$ & 0.0416 \\
\hline Prostate & 142 & 21.1 & 1.06 & $0.56-2.00$ & 0.8617 \\
\hline Pancreas & 108 & 24.1 & 1.25 & $0.65-2.42$ & 0.5037 \\
\hline Stomach & 99 & 20.2 & 1.00 & - & - \\
\hline \multicolumn{6}{|l|}{ Breakthrough pain } \\
\hline Yes & 870 & 24.2 & 1.00 & - & - \\
\hline No & 927 & 26.4 & 1.14 & $0.92-1.41$ & 0.2409 \\
\hline \multicolumn{6}{|l|}{ Neuropathic pain } \\
\hline Yes & 455 & 24.8 & 1.00 & - & - \\
\hline No & 1314 & 25.2 & 1.02 & $0.80-1.30$ & 0.8806 \\
\hline \multicolumn{6}{|c|}{ Analgesic adjuvant therapy } \\
\hline Yes & 1078 & 18.1 & 1.00 & - & - \\
\hline No & 719 & 36.0 & 2.55 & $2.05-3.17$ & $<0.0001$ \\
\hline
\end{tabular}

${ }^{\mathrm{a}}$ Only cancers with frequency $>5 \%$.

related to the disease and treatments that become major contributors to suffering. Considerable evidence from clinical experience shows that cancer pain may be controlled in up to $90 \%$ cases with available therapies (Ventafridda et al, 1987; Grond et al, 1996; Mercadante, 1999). The epidemiology of cancer pain and related treatments in Italy is not well documented, but undertreatment is to be expected as strong opioids are prescribed only to a small proportion of eligible patients. (De Conno et al, 2005; Osservatorio Nazionale sull'impiego dei farmaci, 2007). This study reporting the results of an observational study produced a significant picture of the management of cancer pain for an unselected population of cancer patients in the care of different Italian specialist facilities (oncology clinics, pain and palliative care and hospice centres). Forthcoming studies will describe the longitudinal change over time of both therapeutic and outcome variables and will compare the effectiveness of different analgesic strategies (Apolone et al, 2006b).

The main aim of this analysis was to estimate the quality of analgesic drug regimens across different settings. We applied the PMI as recommended by Cleeland et al (1994) using the worst
Table 5 Multivariate association (multivariable logistic regression) between selected variables and PMI negative scores

\begin{tabular}{|c|c|c|c|}
\hline & OR & $95 \% \mathrm{Cl}$ & $P$-value \\
\hline \multicolumn{4}{|l|}{ Age (years) } \\
\hline$<51$ & 1.00 & $0.69-1.46$ & 0.9916 \\
\hline $51-60$ & 1.04 & $0.75-1.44$ & 0.8021 \\
\hline $61-70$ & 1.00 & - & - \\
\hline$>70$ & 1.21 & $0.91-1.62$ & 0.1870 \\
\hline \multicolumn{4}{|l|}{ Sex } \\
\hline Male & 1.00 & - & - \\
\hline Female & 1.21 & $0.96-1.53$ & 0.1082 \\
\hline \multicolumn{4}{|l|}{ Bone metastasis } \\
\hline Yes & 1.00 & - & - \\
\hline No & 1.05 & $0.82-1.35$ & 0.6795 \\
\hline \multicolumn{4}{|l|}{ Ongoing chemotherapy } \\
\hline Yes & 1.00 & - & - \\
\hline No & 1.17 & $0.9|-| .5 \mid$ & 0.2195 \\
\hline \multicolumn{4}{|l|}{ Type of recruiting centre } \\
\hline Palliative care+pain centre & 2.09 & $1.27-3.45$ & 0.0038 \\
\hline Oncology centre & 2.09 & $1.26-3.45$ & 0.0041 \\
\hline Hospice & 1.00 & - & - \\
\hline \multicolumn{4}{|l|}{ Type of cancer } \\
\hline Pancreas & 1.00 & - & - \\
\hline Colorectal & 1.43 & $0.82-2.48$ & 0.2047 \\
\hline Gynecologic & 1.42 & $0.80-2.51$ & 0.2282 \\
\hline Others & 1.15 & $0.69-1.91$ & 0.5865 \\
\hline \multicolumn{4}{|l|}{ Breakthrough pain } \\
\hline Yes & 1.00 & - & - \\
\hline No & 1.09 & $0.86-1.37$ & 0.4793 \\
\hline \multicolumn{4}{|l|}{ Neuropathic pain } \\
\hline Yes & 1.14 & $0.87-1.49$ & 0.3514 \\
\hline No & 1.00 & - & - \\
\hline \multicolumn{4}{|l|}{ Analgesic adjuvant therapy } \\
\hline Yes & 1.00 & - & - \\
\hline No & 2.40 & $1.89-3.04$ & $<0.0001$ \\
\hline \multicolumn{4}{|l|}{ Time of recruiting } \\
\hline Already admitted & 1.00 & - & - \\
\hline New cases & 2.46 & $1.88-3.20$ & $<0.000$ \\
\hline
\end{tabular}

intensity of pain to calculate the score. By changing the pain measure criteria, it yields figures which cannot be fully compared, as suggested by earlier research (de Wit et al, 1999).

The prevalence of undertreatment found in this study $(25 \%$ in the whole sample and up to $55 \%$ in some groups) compares the earlier results ranging from as low as $7-9 \%$ in a survey in the United Kingdom (Russell et al, 2006) to $82 \%$ in a sample of nonsmall cell lung cancer patients entering clinical trials in Italy (Di Maio et al, 2004), with the weighted overall mean of $43 \%$ across 26 different studies (Deandrea et al, 2008).

When the factors associated with negative PMI were examined in this study, undertreatment tended to be lower according to the year of publication, showing a time trend between articles published before and after 2000; it was also associated with socioeconomic and geographic factors: patients coming from Asian countries and patients with lower socioeconomical status had the highest risk of undertreatment. Other factors that predict a negative PMI consistently were having a less advanced disease and the discrepancy between the patient's and physician's assessments of pain intensity (Russell et al, 2006; Deandrea et al, 2008). 


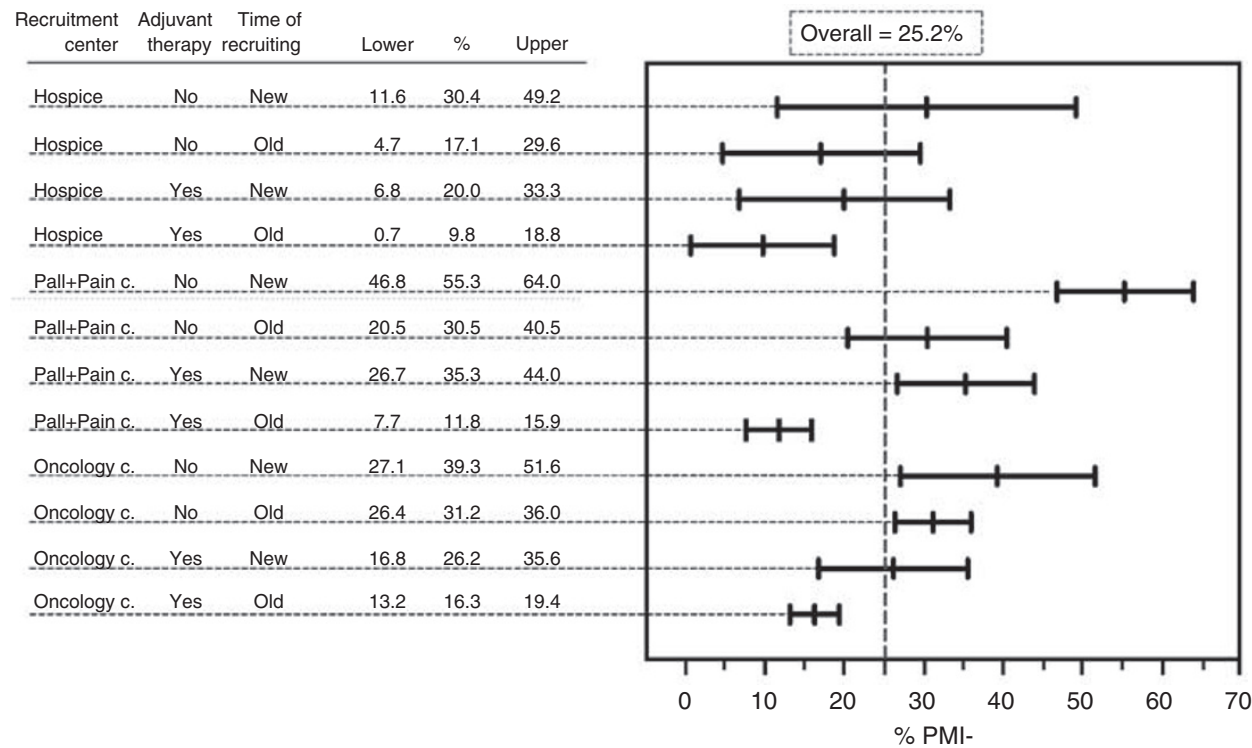

Figure 3 Percentages ( $95 \%$ confidence interval) of patients with negative PMI in all the combinations among levels of recruiting centres, adjuvant therapy and time of recruiting.

This study shows that the baseline PMI scores are also influenced by the time of referral. Patients just referred to a centre had negative PMI more often $(41 \%)$ than patients already followed by the centre. This factor has been underestimated in the literature and it should, therefore, be stressed that the patient's pain history is a significant variable in evaluating epidemiological and therapy-related information. A selection bias can also have occurred in our study as physicians may have referred those patients who needed expert advice for treating their pain, although $20 \%$ of negative PMI persisted also in patients referred to the centre since a long time (Table 3 ).

In this study, the setting of care and receiving an adjuvant analgesic drug treatment were also predictors of the PMI status. Being admitted to a hospice and the use of an adjuvant drug were in fact independently associated with more adequate analgesic treatments. These observations might be interpreted as indicative of a delay of starting strong opioids influenced by attitudes of practice and setting of care. Time of patient referral to the centre, considered as very important, is not enough to explain pain and pain treatment history. Organisation and expertise in pain management and monitoring by different specialists and in different settings, such as an in-patient hospice or outpatient pain clinic, probably influence the recourse to more potent drugs.

The use of adjuvants for neuropathic pain is an indicator of compliance with available guidelines (SIGN, 2008), and perhaps its association with more appropriate opioid use is consistent in explaining individual differences among operators even in apparently similar settings.

Although the usefulness of the PMI is proved by the large number of studies that have used this score since 1994, some drawbacks are well known (Deandrea et al, 2008) and others may be derived from our analysis. It takes into account only one characteristic of pain (the intensity) and the most potent opioid prescribed, but does not reflect other pain characteristics, opioid titration, route of administration, patient's compliance, rescue and adjuvant therapies, or the use of non-pharmacological therapies. For instance, for patients with neuropathic pain and severe pain, it might be more appropriate to add an adjuvant drug for neurophatic pain rather than changing the type of analgesic drugs or increase its dosage. Eventually, PMI is a static measure that allows cross-sectional evaluation, but cannot adequately assess events over time. Given the longitudinal nature of the study, we were also able to prospectively evaluate the PMI negative status at 4 weeks. As expected, as it is very sensitive to the administration of opioids, the proportion of undertreatment falls substantially approaching 5\%, with little variability across variables (type of centre and patient). As a conclusion, PMI can be viewed as a preliminary indicator (a screener) of potential undertreatment that requires a further more specific evaluation.

When we used a selected list of indicators to describe the attitude of Italian physicians towards treating subgroups of patients with specific clinical conditions, we found that the general picture captured by PMI does reflect substantial undertreatment. These indicators also added important information about less than optimal practices. Only 59\% of patients with severe worst pain actually received a strong opioid as 'around the clock therapy' at the time of study enrolment, $44 \%$ with neuropathic pain had an adjuvant drug prescribed and $24 \%$ with breakthrough pain had a 'rescue' analgesic. The interpretation of the fact that only $38 \%$ of patients with bone metastasis actually were receiving bisphosphonates is less straightforward as the role of these drugs to obtain immediate pain relief remains uncertain, despite results from a Cochrane Review document that the addition of bisphosphonates can be beneficial (Wong and Wiffen, 2002). Interestingly, also these indicators were associated with the place of care.

In summary, in this prospective observational study, the PMI method indicated a high prevalence of analgesic undertreatment in Italy, around $50 \%$ in some subgroups, which varies according to several factors related to the characteristics of the cases and to some structural and organisation variables. These findings confirm the results of a systematic review (Deandrea et al, 2008). Other clinical indicators suggest that undertreatment is substantial in some specific subgroups, with underuse of specific adjuvant drugs. Recourse to the WHO third-level drugs is still delayed in a large percentage of patients with cancer pain, half of whom are still treated with anticancer drugs, but very few (31\%) had adequate information about prognosis.

It is likely that after the first impact of the WHO guidelines on cancer pain after their first publication in 1986, the present overall strategy for managing cancer pain in Italy would need more structured interventions to improve and standardise quality of 
Table 6 Compliance with selected indications according to specific subgroups

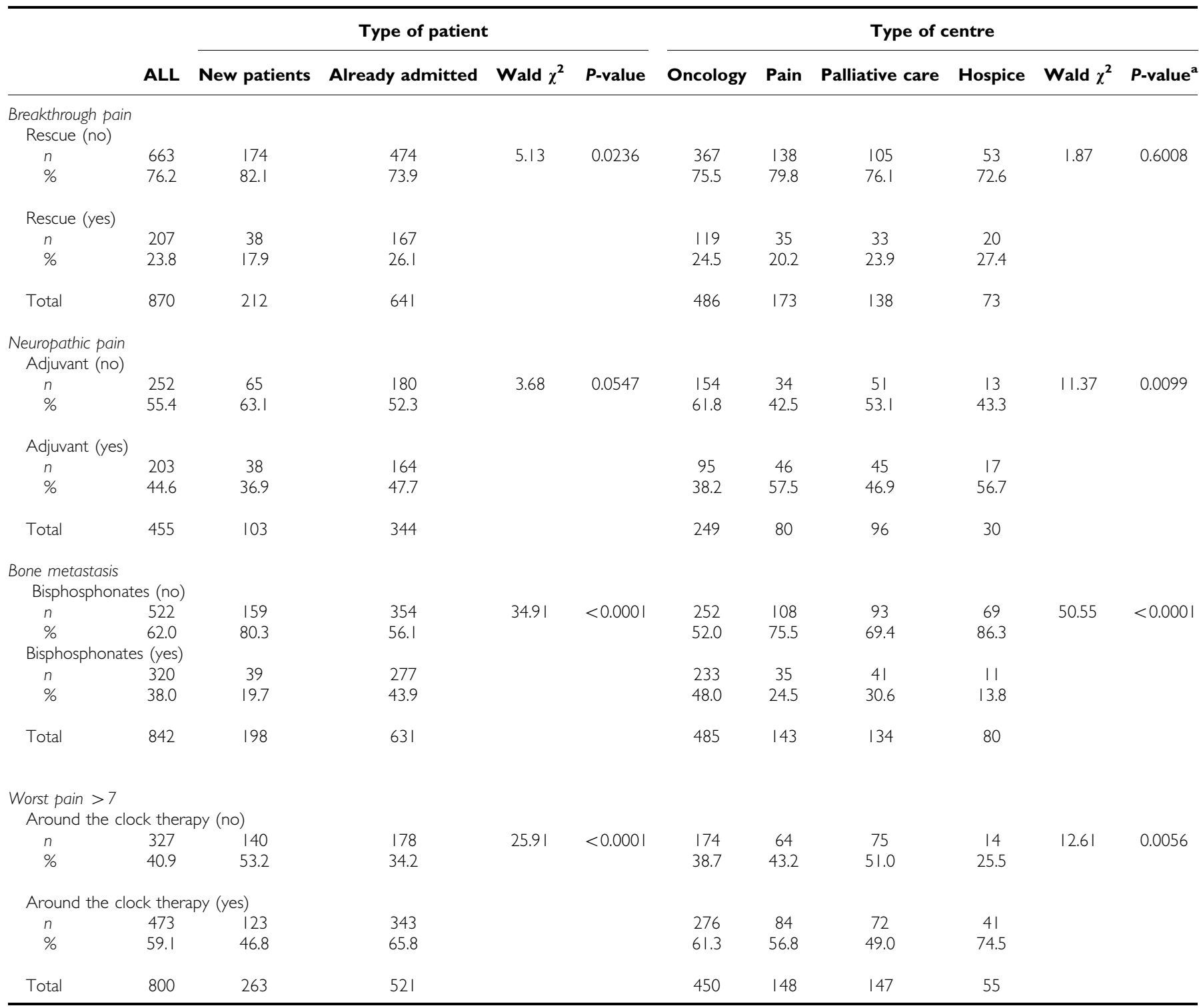

aLogistic regression test.

care. Evidences about the most effective interventions in changing the outcome of current practice in cancer pain management are scarce. Although guidelines implementation proved to have an impact on patient-reported outcomes (Ventafridda et al, 1990; Du Pen et al, 1999), educational and quality improvement programmes had no effect in modifying patients' pain severity, but a beneficial effect was seen as the result of providing specialised palliative care (Goldberg and Morrison, 2007). Others have advocated the efficacy of the implementation of institutional policies, adoption of clinical pathways and pain consultation models (Brink-Huis et al, 2008). In Italy where lack of homogeneous service development for patients with cancer pain, cultural barriers and poor guidelines dissemination are likely to exist, a combination of approaches adopted by professional and scientific associations, regulatory authorities and institutions could improve the way in which the pain is managed in this patient population.

Our results also support the idea that palliative care, like the prevention and relief of symptoms in cancer patients, needs to be a component of patient care also during anticancer treatment, and not merely at the end of life. A wider approach is therefore needed, with better education on palliative care and pain management to improve the use of opioids, to standardise the practice of managing cancer pain to minimum standards (Maltoni, 2008; Meyers et al, 2004) and to improve the physician-patient communication (Harrington and Smith, 2008).

\section{ACKNOWLEDGEMENTS}

We are indebted to Mrs Simona Stupia for secretarial and technical assistance.The project described in this study is supported by an unconditional grant from Grunenthal Italy.

\section{Conflict of interest}

Drs Apolone, Corli and Caraceni have received consulting and lecture fees from Grunenthal Italy. 


\section{REFERENCES}

Apolone G, Bertetto O, Caraceni A, Corli O, De Conno F, Labianca R, Maltoni M, Nicora M, Zucco F, Cancer Pain Outcome Research Study Group (2006a) Pain in cancer. An outcome research project to evaluate the epidemiology, the quality and the effects of pain treatment in cancer patients. Health Qual Life Outcomes 14: 4-7

Apolone G, Mangano S, Compagnoni A, Negri E, Mosconi P, Mannino S, Villa M, Zuccaro P, Cancer Pain Outcome Research Study Group (CPOR SG) (2006b) A Multidisciplinary Project to improve the quality of cancer pain management in Italy. Background, methods, and preliminary results. J Ambul Care Manage 29: $332-341$

Apolone G, Mosconi P, Colombo P, Tamburini M (2004) Il dolore nel paziente con cancro: un progetto di ricerca. Ricerca Pratica 20: $137-143$

Apolone G, Corli O, Greco MT, Zagonel V (2008) Factors influencing the decision to take or reject opioids for cancer pain: are we on target? Ann Oncol 19(5): $1021-1022$

Brink-Huis A, van Achterberg T, Schoonhoven L (2008) Pain management: a review of organisation models with integrated processes for the management of pain in adult cancer patients. J Clin Nurs 17: 1986-2000

Caraceni A, Mendoza T, Mencaglia E, Baratella C, Edwards K, Forjaz MJ, Martini C, Serlin RC, de Conno F, Cleeland CS (1996) A validation study of the Italian version of the Brief Pain Inventory (Breve Questionario per la Valutazione del Dolore). Pain 65: 87-92

CEVEAS: Centro per la valutazione della efficacia della assistenza sanitaria (2004) Morfina orale e altri oppioidi nel dolore oncologico. Aggiornamento sui farmaci no. 9, October, http://www.ceveas.it/flex/cm/pages/ ServeBLOB.php/L/IT/IDPagina/25

Cleeland CS, Gonin R, Hatfiled AK, Edmonson JH, Blum RH, Stewart JA, Pandya KJ (1994) Pain and its treatments in outpatients with metastatic cancer. $N$ Engl J Med 330: $592-596$

Clivio L, Tinazzi A, Mangano S, Santoro E (2006) The contribution of information technology: towards a better clinical data management. Drug Dev Res 67: 245-250

Cohen MZ, Easley MK, Ellis C, Hughes B, Ownby K, Rashad BG, Rude M, Taft E, Westbrooks JB, for the JCAHO (2003) Cancer pain management and the JCAHO's Pain Standards. An institutional challenge. J Pain Symptom Manage 25: 519-527

De Conno F, Ripamonti C, Brunelli C (2005) Opiods purchase and expenditures in nine western European countries: are we killing off morphines? Palliat Med 19: 179-184

de Wit R, van Dam F, Abu-Saad HH, Loonstra S, Zandbelt L, van Buuren A, van der Heijden K, Leenhouts G (1999) Empirical comparison of commonly used measures to evaluate pain treatment in cancer patients with chronic pain. J Clin Oncol 17: 1280-1287

Deandrea S, Montanari M, Moja L, Apolone G (2008) Prevalence of undertreatment in cancer pain. A review of published literature. Ann Oncol 19: 1985 - 1991

Di Maio M, Gridelli C, Gallo C, Manzione L, Brancaccio L, Barbera S, Robbiati SF, Ianniello GP, Ferraù F, Piazza E, Frontini L, Rosetti F, Carrozza F, Bearz A, Spatafora M, Adamo V, Isa L, Iaffaioli RV, Di Salvo E, Perrone F (2004) Prevalence and management of pain in Italian patients with advanced non-small-cell lung cancer. Br J Cancer 90: 2288-2296

Du Pen SL, Du Pen AR, Polissar N, Hansberry J, Kraybill BM, Stillman M, Panke J, Everly R, Syrjala K (1999) Implementing guidelines for cancer

\section{APPENDIX}

\section{Protocol Writing Committee}

Giovanni Apolone: Istituto di Ricerche Farmacologiche 'Mario Negri', Via Giuseppe La Masa 19, 20156 Milan, Italy; Oscar Bertetto: Oncologia Medica, Ospedale Molinette, Corso Bramante 88, 10126 Turin, Italy; Augusto Caraceni: Unità Operativa Cure Palliative, Istituto Nazionale dei Tumori, Via Venezian 1, 20123 Milan, Italy; Oscar Corli: Istituto di Ricerche Farmacologiche 'Mario Negri', Via Giuseppe La Masa 19, 20156 Milan, Italy; Franco De Conno: Unità Operativa Cure Palliative, Istituto Nazionale dei Tumori, Via Venezian 1, 20123 Milan, Italy; Roberto Labianca: Oncologia Medica, Ospedali Riuniti di Bergamo, Largo Barozzi 1, 24100 Bergamo, Italy; Marco Maltoni: Hospice Forlimpopoli, ASL Forli Cure Palliative, Via Duca D’Aosta 33, 47034 Forlimpopoli pain management: results of a randomized controlled clinical trial. J Clin Oncol 17: $361-370$

Goldberg GR, Morrison RS (2007) Pain management in hospitalized cancer patients: a systematic review. J Clin Oncol 25: 1792-1801

Grond S, Zech D, Diefenbach C, Radbruch L, Lehman KA (1996) Assessment of cancer pain: a prospective evaluation in 2266 cancer patients referred to a pain service. Pain 64: $107-114$

Hanks G, De Conno F, Cherny N, Hanna M, Kalso E, McQuay HJ, Mercadante S, Meynadier J, Poulain P, Ripamonti C, Radbruch L, Casas JR, Sawe J, Twycross RG, Ventafridda V, Expert Working Group of the Research Network of the European Association for Palliative Care (2001) Morphine and alternative opioids in cancer pain the EAPC recommendations. Br J Cancer 84: 587-593

Harrington SB, Smith TJ (2008) The role of chemotherapy at the end of life: 'When is enough, enough?'. JAMA 299: 2667-2678

Hearn J, Higginson IJ (2003) Cancer pain epidemiology: a systematic review. In Cancer Pain, Assessment and Management Bruera ED, Portenoy RK (eds) Cambridge University Press: Cambridge

Jacox A, Carr DB, Payne R (1994) New clinical-practice guidelines for the management of pain in patients with cancer. N Engl J Med 330: 651 - 655

Mercadante S (1999) Pain treatment and outcomes for patients with advanced cancer who receive follow-up care at home. Cancer 85: 1849-1858

Maltoni M (2008) Opioids, pain, and fear. Ann Oncol 19: 5-7

Meyers FJ, Linder J, Beckett L, Christensen S, Blais J, Gandara DR (2004) Simultaneous care: a model approach to the perceived conflict between investigational therapy and palliative care. J Pain Symptom Manage 28: 548 - 556

Osservatorio Nazionale sull'impiego dei farmaci (2007) Rapporto nazionale gennaio-settembre 2007. L'uso dei farmaci in Italia, http://www.agenziafarmaco.it/allegati/osmed_gs2007.pdf

Reid CM, Gooberman-Hill R, Hanks GW (2008) Opioid analgesics for cancer pain: symptom control for the living or comfort for the dying? A qualitative study to investigate the factors influencing the decision to accept morphine for pain caused by cancer. Ann Oncol 19: 44-48

Russell PB, Aveyard SC, Oxenham DR (2006) An assessment of methods used to evaluate the adequacy of cancer pain management. J Pain Symptom Manage 32: 581 - 588

Scottish Intercollegiate Guidelines Network (2008) Control of pain in adult patients with cancer. A national clinical guidelines http://www.sign.ac. uk/pdf/SIGN106.pdf accessed on 03.03.2009

van den Beuken-van Everdingen MH, de Rijke JM, Kessels AG, Schouten HC, van Kleef M, Patijn J (2007) Prevalence of pain in patients with cancer: a systematic review of the past 40 years. Ann Oncol 18: 1437-1449

Ventafridda V, Tamburini M, Caraceni A, DeConno F, Naldi F (1987) A validation study of the WHO method for cancer pain relief. Cancer 59: $851-856$

Ventafridda V, Caraceni A, Gamba A (1990) Field-testing of the WHO guidelines for cancer pain relief, in Advances in Pain Research and Therapy, vol. 16, In 2nd International Congress on Cancer Pain. Foley KM, Ventafridda V, Bonica JJ (eds), pp 451-464. Raven Press: New York Wong RKS, Wiffen PJ (2002) Bisphosphonates for the relief of pain secondary to bone metastases. Cochrane Database of Systematic Reviews, (Issue 2): Art. No. CD002068. DOI 10.1002/14651858.Cd002068

World Health Organization (1996) Cancer Pain Relief, 2nd edn World Health Organization: Geneva
(FC), Italy; Maria Flavia Nicora: Direzione Medica, GrunenthalFormenti, Via R Koch 1/2, 20152 Milan, Italy; Valter Torri: Istituto di Ricerche Farmacologiche 'Mario Negri', Via Giuseppe La Masa 19, 20156 Milan, Italy; Furio Zucco: Hospice Garbagnate, Cure Palliative A.O. Salvini, Viale Forlanini 121, 20024 Garbagnate Milanese (MI), Italy.

Cancer Pain Outcome Research Study Group Members

V Adamo: UO di Oncologia Medica e Terapie Integrate, Dipartimento di Patologia Umana, Policlinico G Martino, Messina; M Airoldi: SC Oncologia Medica 2, Ospedale San Giovanni Antica Sede, Torino; M Allegri: Servizio Anestesia, Rianimazione I e Tecniche Antalgiche, Fondazione IRCCS Policlinico San Matteo, Pavia; G Altavilla: Oncologia Medica, Dipartimento di Patologia Umana, Università degli Studi di Messina; G Azzarello: UOC Oncologia ed Ematologia Oncologica, ASL 13 Regione Veneto, 
Noale (VE); E Bandieri: Operative Unit Medical Oncology, Carpi Mirandola Hospital, Modena; ML Barzelloni: UO Oncologia, PO 'G da Procida', ASL SA 2, Salerno; F Bassan: UO di Oncologia, Az ULSS n. 4 Regione Veneto, Ospedale di Thiene; G Belfiore: Hospice-Cure Palliative, ASL Chieti; G Bernardo: Oncologia Medica II, Fondazione Salvatore Maugeri (FSM-IRCCS), Pavia; G Bersano: SOC Oncologia, ASL9, Ivrea (TO); R Bertè: UO Oncologia Medica, AO 'Guglielmo da Saliceto', Piacenza; O Bertetto: Centro Oncologico Ematologico Subalpino (COES), Ospedale Molinette, Torino; C Bianchessi: UO Medicina Generale, Ospedale Maggiore di Crema; A Bologna: Servizio di Oncologia, Arcispedale Santa Maria Nuova, Reggio Emilia; S Bravi: UO di Oncologia, ASL n. 1 dell'Umbria, Città di Castello; A Buono: Unità Cure Palliative, AUSL 12 Viareggio (LU); F Buzzi: Oncologia Degenza, Azienda Ospedaliera Terni; C Cacioppo: Hospice SM delle Grazie, Fondazione Don Gnocchi, Monza; J Capuccini: UO Terapia del Dolore e Cure Palliative, ASUR Marche-ZT3, Fano (PU); C Caroti: Osteoncologia e Cure Palliative, SC Oncologia Medica, EO Ospedali Galliera, Genova; G Castagnini: Unità Cure Palliative e Terapia del Dolore, AO San Gerardo, Monza; M Ceste: SOC Oncologia, Ospedale Cardinal Massaia, Asti; S Chisari: Centro di Medicina del Dolore, AO Universitaria 'Vittorio Emanuele, Ferrarotto e S Bambino', Catania; B Chiurazzi: Divisionene di Oncologia, AORN 'A Cardarelli', Napoli; A Comandone: Oncologia, AO Gradenigo, Torino; E Cortesi: Oncologia Medica B, Policlinico Umberto I, Università 'Sapienza', Roma; C Crispino: UOS di Terapie di Supporto, AO 'Monaldi', Napoli; A Cuomo: UOD Terapia Antalgica, Istituto Nazionale Tumori 'Fondazione Pascale', Napoli; A De Martino: UO di Medicina del Dolore e Cure Palliative, Hospice 'Giardino dei Girasoli', DS B di Eboli, ASL Salerno 2; A De Matteis: Oncologia Medica C, Istituto Nazionale Tumori 'Fondazione Pascale', Napoli; A De Salve: Unità di Cure Palliative e Terapia del Dolore, Ospedale Bassini, AO San Gerardo di Monza; S Del Prete: UOC Oncologia, Ospedale 'San Giovanni di Dio', Frattamaggiore (NA); F Della Rovere: UOS Terapia Antalgica e Cure Palliative, AO Universitaria San Martino, Genova; C Dello Ioio: Assistenza Domiciliare Oncologica Integrata, ASL Salerno 1, Salerno; S Derni: Unità Cure Palliative, Dipartimento Oncologico, AUSL Forlì; L Di Alesio: Dipartimento Oncologico, POS Andrea Felettino, ASL n. 5 Regione Liguria, La Spezia; F Di Costanzo: Struttura Oncologica Complessa, A.O. Universitaria Careggi, Firenze; C Di Fonzo: UOC Oncologia Medica Ospedaliera, Ospedale 'Santa Maria Goretti', Latina; R Di Gregorio: Terapia Antalgica, Ospedale Sacro Cuore di Gesù Fatebenefratelli, Benevento; M Di Lanno: Servizio Oncologia, Ospedale 'San Giuliano', Distretto 58 ASL NA 2, Giugliano in Campania (NA); M Di Seri: UOC Oncologia A, Policlinico Umberto I, Università 'Sapienza', Roma; M Di Stefano: Anestesia e Rianimazione, Centro Tumori Ascoli; D Dini: Terapie Palliative - Hospice, Centro Oncologico AO Modena; D Dini: SC Terapia Antalgica e Riabilitazione, Istituto Nazionale per la Ricerca sul Cancro, Genova; M Duro: UO di Oncologia, Ospedale Valduce, Como; G Facchini: Oncologia Medica B, Istituto Nazionale Tumori 'Fondazione Pascale', Napoli; A Farris: Oncologia Medica Universitaria, Sassari; C Ferrara: UO di Oncologia Medica, AO 'San Giuseppe Moscati', Avellino; P Ferrari: UO Cure Palliative, Fondazione Maugeri, Ospedale San Martino, AO Provincia di Pavia, Mede (PV); M Frascaroli: Riabilitazione Oncologica, Fondazione Maugeri IRCCS, Pavia; D Furiosi: USS Terapia Antalgica e Cure Palliative, AO della Provincia di Lodi; F Fusco: UOS Cure Palliative Polo Ponente, ASL n. 3 Genovese, Genova; V Gebbia: UO Oncologia Medica, Dipartimento Oncologico III livello, Casa di Cura di Alta Specialità 'La Maddalena', Palermo; MG Ghi: Oncologia Medica, Azienda ULSS n. 12, Venezia Mestre; D Giannunzio: UO Cure Palliative, Azienda Istituti Ospedalieri, Cremona; C Giuffrè: Divisione di Oncologia Medica, AO Bianchi Melacrino Morelli, Reggio Calabria; C Guarino: II UOC di Pneumologia Oncologica, AO 'Monadi', Napoli; F Henriquet:
Associazione Gigi Ghiotti 'ONLUS' - Assistenza domiciliare e in Hospice, Genova; L Isa: Divisione Oncologia Medica, Ospedale 'Serbelloni', Gorgonzola (MI); P La Ciura: SC Cure Palliative e Hospice, ASL CN 1, Cuneo; F La Rocca: Unità Funzionale Cure Palliative, ASL 6 Livorno; R Labianca: UO di Oncologia Medica, Ospedali Riuniti di Bergamo; C Longhi: UOS Cure Palliative Domiciliari - Hospice 'Il mantello, Struttura di Mariano Comense, AO Sant'Anna Como; G Lupo: Oncologia Medica e Terapie Innovative, Dipartimento di Patologia Umana, Università degli Studi di Messina; S Mameli: UO Medicina del Dolore, Ospedale 'A Businco', Cagliari; A Manni: Hospice Casa Madonna dell'Uliveto, Albinea (RE); L Manzione: UO Oncologia Medica, AO San Carlo, Potenza; C Martini: Hospice, Istituto Nazionale Tumori, Milano; A Martoni: Oncologia Medica, AO Universitaria, Policlinico S Orsola-Malpighi, Bologna; N Marzano: UO Oncologia, Ospedale 'San. Paolo', ASL/BA, Bari; S Masseroni: Oncologia, AO 'S Carlo Borromeo, Milano; V Mattioli: UO di Medicina del Dolore e Cure Palliative, IRCCS Istituto Tumori 'Giovanni Paolo II', Bari; P Maurizi: Unità di Cure Palliative-Sez. Dipartimentale del Dip.to Oncologico, Azienda ULS 8, Arezzo; D Miotti: UO di Cure Palliative e Terapia del Dolore, Fondazione Salvatore MaugeriIRCCS, Pavia; L Montanari: UO Oncologia Medica, Ospedale di Lugo, AUSL Ravenna; L Moscetti: UOC di Oncologia, Ospedale Belcolle, ASL Viterbo; V Murgia: Oncologia Medica, Ospedale Santa Chiara, Trento; LF Nardi: UO Terapia del Dolore e Cure Palliative, Zona territoriale 9, ASUR Marche, Macerata; F Narducci: Oncologia Medica, Ospedale SS Trinità, Sora (FR); F Negri: Divisione di Medicina e Oncologia Medica, Azienda Istituti Ospedalieri, Cremona; C Orlandini: UO Oncologia Medica, AO Universitaria Pisana, Pisa; D Ottaviani: Centro Universitario di Ricerca Oncologica, Ospedale Molinette, Torino; G Pancera: Medical Oncology Department, Igea Hospital, Milan; F Paoletti: Servizio Aziendale Cure Palliative-Hospice, USL n. 2 dell'Umbria, Assisi; A Pappalardo: UO di Oncologia Medica, Centro Clinico e Diagnostico 'GB Morgagni', Catania; MK Paris: Oncologia Medica, Polo Oncologico di Biella; C Pittureri: Servizio Cure Palliative-Hospice, AUSL Cesena, Savignano sul Rubicone (FC); L Piva: Unità di Cure Palliative, UO Oncologia Medica, AO San Paolo, Milano; L Ponchio: Divisione di Oncologia Medica I, Fondazione Salvatore Maugeri, Pavia; C Reale: UOC Anestesia e Rianimazione C, Policlinico 'Umberto I', Università 'Sapienza', Roma; A Rinaldi: UO Oncologia, OC Castellaneta, AUSL Taranto Polo Occidentale; E Romagnoli: UO Oncologia, Ospedale Civile di Macerata; A Russo: Oncologia Medica, Policlinico Universitario 'P Giaccone', Palermo; C Sandomenico: Oncologia Medica A, Istituto Nazionale Tumori 'Fondazione Pascale', Napoli; A Sbanotto: Unità di Terapie di Supporto e Cure Palliative, Istituto Europeo di Oncologia, Milano; F Scanzi: UO Oncologia, IRCCS Multimedica, Sesto S Giovanni (MI); I Schiavetto: Oncologia Medica Falk, Ospedale Niguarda 'Ca' Granda', Milano; L Trentin: UO Terapia del Dolore e Cure Palliative, Az ULSS n. 6 Ospedale San Bortolo, Vicenza; M Tucci: AO Universitaria San Luigi, Orbassano, Torino; G Vaccaro: Anestesia e Rianimazione, UOS di Terapia del Dolore, PO 'Abele Ajello', Mazara del Vallo (TP); D Valenti: Fondazione Hospice MTC Seragnoli, Bentivoglio, Bologna; VM Valori: Divisione di Oncologia, Casa Sollievo della Sofferenza, San Giovanni Rotondo (FG); G Vasini: UO Oncologia Medica, AO Universitaria, Parma; E Veltri: Centro Oncologico 'Ettore MS Conti', Presidi Ospedalieri di Gaeta e Terracina, ASL Latina; V Zagonel: UOC Oncologia, Ospedale 'San Giovanni Calibita', Isola Tiberina, Roma; E Zecca: Unità di Cure Palliative (Terapia del Dolore - Riabilitazione), Istituto Nazionale Tumori, Milano; G Zeppetella: UOC di Fisiopatologia, terapia del dolore e cure palliative, AO San Sebastiano, Caserta; M Ziliotti: Cure Palliative, Presidio Ospedaliero di Fidenza; F Zucco: Unità Cure Palliative e Terapia del Dolore, AO 'G Salvini', Garbagnate Milanese (MI). 